Suchum, in the same latitude and in a very similar situation as Cannes, in March, 1874, a year with a considerable number of sunspots, there were three days which were more than $27^{\circ}$ colder than the average, while in March, 1883 , with little or no sunspots, the coldest days mentioned by Mr. Williams at Cannes was only $17^{\circ} \cdot 3$ colder than the average.

I want only to show by this example that if it is wished to prove anything as to the varying intensity of the sun's rays, a large number of observations in distant countries should be given, especially in middle latitudes, the work of Dové having well proved that there is always a compensation to a certain extent between cold and warm areas, and a very great number of these deviations being certainly due to causes which have nothing to do with anything beyond the earth's atmosphere.

St. Petersburg, April 17

A. WOEIKOF

\section{Sheet Lightning}

LookIng to the sonth and south-east from the Bel Alp, the play of silent lightning among the clouds and mountains is sometimes very wonderful. It may be seen palpitating for hours, with a barely appreciable interval between the thrills. Most of those who see it regard it as lightning without thunder-Blitz ohne Donner, Wetterleuchten, I have heard it named by German visitors.

The Monte Generoso, overlooking the Lake of Lugano, is about fifty miles from the Bel Alp as the crow flies. The two points are connected by telegraph; and frequently when the Wetterleuchten, as seen from the Bel Alp, was in full play I have telegraphed to the proprietor of the Monte Generoso Hotel, and learnt in every instance that our silent lightning coexisted in time with a thunderstorm more or less "terrific" in Upper Italy.

May 12

JOHN TYNDALI

I AM glad to find that M. Antoine d'Abbadie's remarks confirm in the main those which I have made on the above subject in NATURE (vol. xxviii. p. 4), especially as to the occurrence of lightning at a great altitude as observed in low latitudes.

In stating that he has frequently observed "thunder without lightning, and lightning without thunder," does M. d'Abbadie mean that, like every one else, he has observed thunder withou observing lightning, and lightning without observing thunder? Or have we here a living advocate not only of the dumb lightning, but of the dark (lightningless) thunder?

The thin and local fogs which are not uncommon in thundery weather readily transmit the illumination of a distant flash of lightning. It seems highly probable that in such cases the lightning may be occasionally supposed to be an electric discharge occurring in the fog itself, just as a flickering aurora seen above thin clouds has often been supposed to have its habitat in the clouds themselves.

The suggestion of M. d'Abbadie is a fair one, and I for my part shall be glad to undertake observations of "sheet lightning" this summer in conjunction with any one resident about forty miles from this place, the observers interchanging reports by the earliest post after the hour of observation.

\section{Ashby Parva, Lutterworth, Leicestershire}

$$
\text { W. Cremen's Ley }
$$

\section{Hydrogen Whistles}

IN his interesting communication on the above topic (NATURE, vol. xxvii. p. 49I) Dr. Francis Galton has inadvertently fallen into a mistake which quite seriously afferts the numerical deductions which follow. He erroneously assumes that "the number of vibrations per second caused by whistles is inversely proportional to the specific gravity of the gas that is blown through them."

It is well known that the number of vibrations is inversely proportional to the square root of the density or specific gravity of the gas. Hence for hydrogen, as compared with air, the number of vibrations per second produced by a given whistle would be increased only about $3 \cdot 6$-fold instead of 13 -fold, as he estimates it. Similarly the number of vibrations by the use of hydrogen in the little whistle when set at 0.14 inches would be only about 86,533 , instead of 312,000 .

Berkeley, Cal., April I2
[THE objection of your correspondent is valid. I am informed independently and by high authority that the velocity of sound in hydrogen must be considered as barely fourfold greater than in air, the number of vibrations per second emitted by a hydrogen whistle being increased in the same proportion.

In making my earlier estimate I had been misled by an erroneous statement in a work that is still of much general credit and authority, to which I referred for ascertaining the velocity of sound in different gases, as it happened to be the book then nearest at hand, and as I have no special knowledge of the subject. It was the first edition of the Penny Cyclopadia, where in the article "Acoustics," p. 95, I lit upon the following passage, which professed to give the precise information I wanted:- "Thus air being about thirteen times as heavy as hydrogen, the velocity of propagation in the latter is about thirteen times that in the former." I need not take up your space by quoting the paragraphs before and after this, which emphasise and corroborate the statement and make it clear that it was no slip of the pen. Possessors of this Cyclopædia (I know nothing of subsequent editions) would do well to look out the passage and put a note of warning by the side of it.

The fourfold gain, or nearly so, of the hydrogen whistle is not to be despised. It is sufficient to establish its rank as the emitter of the largest number of aërial vibrations per second of any instrument yet contrived. My little whistle, of about $\mathrm{I} \mathrm{mm}$. bore, requires a very small supply of air, a bag that I fill with a single expiration containing enough to keep it in continuous sound for many minutes. As yet I have not got a portable holder for pure, dry hydrogen, but a well-known chemist is kindly making an experiment of one for me.

Francis GaLtoN]

\section{The Pillar of Light}

I HAVE frequently observed this phenomenon. The first time I saw it was on April 8, 1852, when I saw it here at sunset, and on April II I saw it at sunrise when I was in the Irish Channel, near to Port Patrick, where I was laying a submarine cable.

In the Monthly Notices of the R.A.S. vol. xii. p. 185, there are several notices of its having been seen at that time in various places. I saw it last on April 6 this year, when it had the same appearance as previously, which is well represented by $\mathrm{Mr}$. Symond's drawing on p. 7 , except that the lower part is too bright, and it looks more correct when shaded with a pencil. The pillar is always perpendicular to the horizon and to the sun's position. I saw the zodiacal light several times in February, extending as far as the Pleiades, and at an angle of about $45^{\circ}$. I think it is highly probable that the pillar of light is caused by reflection from ice crystals, as we had very cold weather early in April, and have still. These atmospheric phenomena are often best seen reflected from a plate gla-s window.

Gateshead, May 9

R. S. Newall

\section{Remarkable Lunar Phenomenon observed at Weston- super-Mare, August 21, 186I}

AT about 8.30 p.m. a band of silvery light appeared proceeding from the lower margin of the moon, in a line perpendicular to the horizon. The width of this band was equal to the exact apparent diameter of the moon's disk. Slowly the band lengthened, until its upper portion reached beyond the moon to the extent of about two diameter:, while the lower limb extended itself to about the length of four diameters, where its foot rested apparently on a light fleecy cloud. In a few minutes a similar band traversed the other at right angles, forming a perfect Latin crosi, the brilliant face of the moon occupying the place of intersection. The armis of the cross were respectively about two diameters of the moon's face. The portion of the sky in which this occurred was clear, but clouds were slowly drifting from the west, and in ten minutes began to obscure this beautiful and unusual phenomenon.

The only record of any similar phenomenon which I can meet with is to be found in Lowe's treatise on atmospheric phenomena, wherein two in tances are described. The observer of one was Dr. Armstrong, and the appearance was seen by him at South Lambeth on February 25, 1842. The other observer was Mr. Lowe himself, who was at Derby railway station when the phenomenon occurred. In both these instances, however, the crossbeam was absent. Although no hypothesis has been suggested to account for this appearance, it may be interesting to note that in the case recorded by Mr. Lowe, the very 